\title{
Pengaruh Kinerja Lingkungan Dan Leverage Terhadap Pengungkapan Corporate Social Responsibility Pada Perusahaan Sektor Pertambangan, Kimia Dan Pertanian Yang Terdaftar Di Bursa Efek Indonesia Tahun 2014-2016
}

\author{
Hadi Swantara \\ Program Studi Magister Manajemen Universitas Tarumanagara \\ Hadiswantara90@gmail.com
}

\begin{abstract}
The aim of this research was to examine the effect of environmental performance Leverage and Profitability toward corporate social responsibility (CSR) disclosure of mines, chemical and farm company. The environmental performance was measured by the company performance in PROPER. This research attampts to used tree corporate characteristic, they are company Environmental Performance,Leverage and Profitability. Dependent variable used in this research was CSR disclosure. The population of this research is all the Mine,Chemical and Farm company listed in Indonesia Stock Exchange during 2014-2016. The total sample of this research was 96 companies. The collection of research data used purposive sampling method. The data analysis method used is analysis regression. The result showed that environmental performance and Leverage significantly influence to Corporate Social Responsibility Disclosure.
\end{abstract}

Keywords : environmental performance, Leverage And Corporate Social Responsibility Disclosure

\section{PENDAHULUAN}

Sekitar 70\% kerusakan lingkungan yang terjadi di Indonesia disebabkan oleh operasi pertambangan. Industri ini dengan mudah melabrak dan mengakali berbagai aturan yang bertentangan dengan kepentingannya, termasuk undang-undang nomor 32 tahun 2009 tentang pengelolaan dan perlindungan lingkungan hidup (PPLH). Dimana hampir 34\% daratan Indonesia digunakan untuk pertambangan mineral dan batubara (minerba). Belakang ini juga maraknya kampanye anti minyak sawit yang terjadi di Uni Eropa . Hal ini disebabkan Pengunaan Biodiesel konvensional dinilai tidak berkontribusi untuk menekan gas rumah kaca tetapi menyebabkan masalah baru karena pengunaan lahan tidak langsung, Pengunaan lahan tidak langsung ini terjadi ketika penanam sawit untuk bahan dasar biodiesel. Lahan yang seharusnya untuk keperluan pertanian, hutan dan lahan gambut berubah menjadi Lahan sawit.yang mana tujuan untuk mengurangi emisi lewat Biofuel berbasis tanaman sebaliknya menimbulkan emisi gas rumah kaca yang sangat besar. Serta banyaknya perusahaan perusahaan kotor demi kesejahteraanya membakar hutan tampa memperhatikan dampak yang di timbulkan hanya untuk menanam komoditi minyak sawit.

Masalah sosial dan lingkungan yang tidak diatur dengan baik oleh perusahaan ternyata memberikan dampak yang sangat besar, bahkan tujuan meraih keuntungan dalam aspek bisnis malah berbalik menjadi kerugian yang berlipat. Oleh karena itu masalah pengelolaan sosial dan lingkungan untuk saat ini tidak bisa menjadi hal marginal, ditempatkan pada tahap kuratif atau aspek yang tidak dianggap penting dalam beroperasinya perusahaan.

Tanggung jawab sosial perusahaan atau dikenal dengan istilah Corporate Social Responsibility (CSR), merupakan aspek penting yang harus dilakukan perusahaan dalam operasionalnya. Hal tersebut bukan semata-mata memenuhi peraturan perundang - undangan 
sebagaimana untuk perusahaan tambang diatur dalam Undang-undang No 22 tahun 2001, maupun untuk Perseroan Terbatas (PT) diatur dalam Undang undang No. 40 pasal 74 tahun 2007, melainkan secara logis terdapat hukum sebab akibat, dimana ketika operasional perusahaan memberikan dampak negatif, maka akan muncul respon negatif yang jauh lebih besar dari masyarakat maupun lingkungan yang dirugikan.

Pengungkapan Corporate Social Responsibility sebagai bentuk tanggung jawab perusahaan terhadap tanggung jawab social perusahaan merupakan proses pengkomunikasian dampak sosial dan lingkungan dari kegiatan ekonomi organisasi terhadap kelompok khusus yang berkepentingan dan terhadap masyarakat secara keseluruhan. Dimana Informasi nonkeuangan dan keterlibatan sosial perusahaan di komunikasikan kepada para stakeholder. Pengkomunikasian aktivitas tersebut dilakukan dengan berbagai cara dan media pengungkapan. Salah satu alat atau media yang dapat digunakan adalah laporan tahunan. Pengungkapan ( disclose ) berarti penyampaian ( release) informasi.

Penelitian yang dilakukan Permana (2012), menyatakan bahwa Kinerja Lingkungan berpengaruh signifikan positif terhadap pengungkapan Corporate Social Responsibility. Sedangkan Leverage tidak berpengaruh signifikan positif terhadap pengungkapan Corporate Social Responsibility. Penelitian Wijaya (2012), menyatakan bahwa Kinerja lingkungan dan Leverage tidak berpengaruh signifikan positif terhadap pengungkapan Corporate Social Responsibility. Sedangkan Leverage tidak berpengaruh signifikan positif terhadap pengungkapan Corporate Social Responsibility. . Penelitian Dermawan dan Deitiana (2014), menyatakan bahwa Leverage tidak berpengaruh signifikan positif terhadap pengungkapan Corporate Social Responsibility.

Perbedaan penelitian ini dengan penelitian sebelumnya adalah peneliti menggunakan dua variabel independen yaitu Kinerja Lingkungan dan Leverage. Peneliti menggunakan objek yang berbeda yaitu perusahaan pertambangan, Kimia dan Pertanian yang terdaftar di Bursa Efek Indonesia periode 2014-2016.

\section{KERANGKA PEMIKIRAN TEORITIS DAN PERUMUSAN HIPOTESIS}

\section{Corporate Social Responsibility (CSR)}

Corporate Social Responsibility juga merupakan salah satu bentuk sustainability reporting yang memberikan keterangan tentang berbagai aspek-aspek perusahaan mulai dari aspek sosial, lingkungan dan keuangan sekaligus yang tidak dapat dijelaskan secara tersirat oleh suatu laporan keuangan perusahaan saja. (Bahri dan Cahyani , 2016)

Corporate Social Responsibility merupakan serangkaian tindakan perusahaan guna meningkatkan produk sosialnya, memperluas jangkauannya melebihi kepentingan ekonomi eksplisit perusahaan, dengan pertimbangan tindakan semacam ini tidak disyaratkan oleh peraturan hukum. Corporate Social Responsibility juga sebagai investasi sosial bagi perusahaan terhadap masyarakat untuk membantu meningkatkan atau memperbarui sumber daya internal dan kapabilitas perusahaan. Adapun dari sisi eksternal perusahaan, investasi tanggung jawab sosial perusahaan akan meningkatkan reputasi perusahaan.(Barnas et.al.,2016).

\section{Signaling Theory}

Menurut Brigham dan Hauston (2001) isyarat atau signal adalah suatu tindakan yang diambil perusahaan untuk memberi petunjuk bagi investor tentang bagaimana manajemen memandang prospek perusahaan. Sinyal ini berupa informasi mengenai apa yang sudah dilakukan oleh manajemen untuk merealisasikan keinginan pemilik. Informasi yang dikeluarkan oleh perusahaan merupakan hal yang penting, karena pengaruhnya terhadap 
keputusan investasi pihak diluar perusahaan. Informasi tersebut penting bagi investor dan pelaku bisnis karena informasi pada hakekatnya menyajikan keterangan, catatan atau gambaran, baik untuk keadaan masa lalu, saat ini maupun masa yang akan datang bagi kelangsungan hidup perusahaan dan bagaimana efeknya pada perusahaan.

\section{Teori Agensi}

Rindawati dan Asyik (2015) menjelaskan konflik kepentingan antara manajer dengan pemilik menjadi semakin besar ketika kepemilikan manajer terhadap perusahaan semakin kecil. Dalam hal ini manajer akan berusaha untuk memaksimalkan kepentingan dirinya dibandingkan kepentingan perusahaan. Sebaliknya semakin besar kepemilikan manajer didalam perusahaan maka semakin produktif tindakan manajer dalam memaksimalkan nilai perusahaan, dengan kata lain biaya kontrak dan pengawasan menjadi rendah. Manajer perusahaan akan mengungkapkan informasi sosial dalam rangka untuk meningkatkan image perusahaan, meskipun ia harus mengorbankan sumber daya untuk aktivitas tersebut.

\section{Hubungan Kinerja Lingkungan dengan Pengungakapan $C S R$}

Menurut Suratno, dkk ( 2006 ) Informasi mengenai aktivitas atau kinerja perusahaan merupakan suatu hal yang sangat berharga bagi stakeholder khususnya investor. Pengungkapan informasi mengenai hal tersebut merupakan kebutuhan bagi stakeholder. Perusahaan yang memiliki environmental performance yang baik merupakan good news bagi investor dan calon investor. Perusahaan yang memiliki good news yang lebih cenderung akan meningkatkan environmental disclosure dalam laporan tahunannya. Perusahaan yang memiliki tingkat environmental performance yang tinggi akan direspon secara positif oleh investor melalui fluktuasi harga saham. perusahaan. Harga saham perusahaan secara relatif dalam industri yang bersangkutan merupakan cerminan pencapaian economic performance perusahaan.

Penelitian yang dilakukan oleh Rakhiemah (2009), menunjukkan bahwa kinerja lingkungan memiliki pengaruh positif yang signifikan terhadap CSR disclosure yang dilakukan oleh perusahaan.Lain halnya dengan penelitian yang di lakukan Wijaya (2012) yang menunjukan Kinerja Lingkungan tidak berpengaruh terhadap Pengungkapan CSR. Dengan demikian, hipotesis yang diajukan:

H1 : Kinerja Lingkungan memiliki pengaruh Signifikan terhadap Pengungkapan Corporate Social Responsibility.

\section{Hubungan Leverage dengan CSR}

Menurut Belkaoui dan Karpik (1989) menyatakan bahwa informasi social akan mengikuti suatu pengeluaran untuk pengungkapan penurunan pendapatan. Sesuai dengan teori agensi manajemen perusahaan dengan tingkat leverage tinggi akan mengurangi pengungkapan tanggung jawab sosial yang dibuatnya agar tidak menjadi sorotan dari para debt holders. Salah satu rasio leverage yang digunakan seorang investor dalam menemukan solvabilitas suatu perusahaan untuk menjamin keamanan investasi yang dilakukannya agar tidak merugi adalah Debt to Equity Ratio (DER).

Menurut Belkaoui dan Karpik (1989) keputusan untuk mengungkapkan CSR akan mengikuti suatu pengeluaran untuk pengungkapan yang menurunkan pendapatan. Perusahaan dengan rasio leverage yang tinggi mengakibatkan pengawasan yang tinggi dilakukan oleh debtholder terhadap aktivitas perusahaan. Sesuai dengan teori agensi maka manajemen perusahaan dengan tingkat leverage yang tinggi akan mengurangi pengungkapan tanggung jawab sosial yang dibuatnya agar tidak menjadi sorotan dari para debtholders. Oleh karena itu Hipotesis yang di ajukan :

H2 : Leverage memiliki pengaruh Signifikan terhadap Pengungkapan Corporate Social Responsibility 


\section{METODE PENELITIAN}

\section{Subjek dan Objek}

Pada penelitian ini yang menjadi subjek dan objek penelitian ini untuk mengetahui pengaruh Kinerja Lingkungan dan Leverage terhadap pengungkapan Corporate Social Responsibility pada perusahaan sektor Pertambangan, Kimia dan Pertanian yang terdaftar di Bursa Efek Indonesia Tahun 2014-2016.

\section{Sampel}

Populasi yang digunakan dalam penelitian ini adalah seluruh perusahaan Sektor Pertambangan, Kimia dan Pertanian yang tercatat (go-public) di Bursa Efek Indonesia (BEI) selama periode tahun 2014-2016 yang berjumlah 125 perusahaan. Sedangkan metode pengambilan sampel adalah purposive sampling.Sehingga total sampel yang di dapat digunakan berjumlah 32 Perusahaan.

\section{Operasionalisasi variabel}

\section{Variabel Dependen}

a. Pengungkapan Corporate Social Responsibility

Variabel pengungkapan sosial perusahaan diukur dengan metode content analysis. Content analysis adalah suatu metode pengkodifikasian teks dari ciri-ciri yang sama untuk ditulis dalam berbagai kelompok (kategori) tergantung pada kriteria yang ditentukan, Guthrie,et al. (2003). Agar content analysis dapat dilaksanakan dengan cara yang replicable maka dapat dilakukan salah satunya dengan cara checklist. Checklist dilakukan dengan melihat pengungkapan sosial perusahaan dalam 7 kategori yang disebutkan oleh Heckston dan Milne (1996), yaitu : lingkungan, energi, kesehatan dan keselamatan tenaga kerja, lain-lain tenaga kerja, produk, keterlibatan masyarakat dan umum. Ketujuh kategori tersebut terbagi dalam 90 item pengungkapan. Menurut Sembiring (2005), berdasarkan peraturan Bapepam No. VIII.G.2 tentang laporan tahunan ada 12 item dari 90 item pengungkapan yang tidak sesuai untuk diterapkan dengan kondisi di Indonesia. Selanjutnya dilakukan penyesuaian dengan cara menghapuskan 12 item pengungkapan tersebut, sehingga secara total tersisa 78 item pengungkapan. Item pengungkapan dalam penelitian ini kemudian dinyatakan dalam bentuk indeks pengungkapan sosial. Apabila item pengungkapan tersebut ada dalam laporan tahunan perusahaan maka diberi skor 1 , dan jika item pengungkapan tersebut tidak ada dalam laporan tahunan perusahaan maka diberi skor 0. Sehinga di Peroleh Rumus sebagai berikut :

\section{Variabel Independen}

$$
\text { CSRD }=\frac{\text { Jumlah Item Pengungkapan Yang terpenuhi }}{\text { Jumlah Item yang mungkin di Penuhi }}
$$

\section{a. Kinerja Lingkungan}

Kinerja lingkungan ini diukur dari prestasi perusahaan mengikuti program PROPER yang merupakan salah satu upaya yang dilakukan oleh Kementerian Lingkungan Hidup (KLH) untuk mendorong penataan perusahaan dalam pengelolaan lingkungan hidup melalui instrumen informasi. Sistem peringkat kinerja PROPER mencakup pemeringkatan perusahaan dalam lima (5) warna yakni (Rakhiemah dan Agustia 2009):

1. Emas : Sangat-sangat baik, skor $=5$

2. Hijau : Sangat baik, skor $=4$

3. Biru : Baik, skor $=3$

4. Merah : Buruk, skor $=2$

5. Hitam : Sangat buruk, skor $=1$

b. Leverage

Leverage dapat diartikan sebagai tingkat ketergantungan perusahaan terhadap hutang dalam membiayai kegiatan operasinya, dengan demikian leverage juga mencerminkan 
tingkat resiko keuangan perusahaan, Sembiring (2005). Dalam penelitian ini, indikator yang digunakan untuk mengukur tingkat leverage adalah Debt To Equity Ratio (DER). Adapun pengukurannya dengan menggunakan rumus (Gibson, 2009,260) :

\section{Regresi}

$$
D E R=\frac{\text { Total Hutang }}{\text { Total Ekuitas }} \times 100 \%
$$

Pengujian hipotesis dilakukan dengan menggunakan analisis regresi berganda (multiple regression) dengan rumus sebagai berikut:

$\mathrm{CSRD}=\mathrm{a}+\mathrm{b} 1 \mathrm{KL}+\mathrm{b} 2 \mathrm{LEV}+\mathrm{e}$

Dimana :

$\mathrm{a}=$ konstanta

CSRD = Pengungkapan Corporate Social Responsibiliy

$\mathrm{KL}=$ Kinerja Lingkungan

$\mathrm{LEV}=$ Leverage

$\mathrm{e}=$ Error

b1, b2, b3 = koefisien regresi

\section{Data dan analisis data}

Tabel 2

Hasil EstimasiRegresi Panel dengan model Fix Effect

Dependent Variable: CSRD

Method: Panel Least Squares

Date: 05/31/18 Time: 05:21

Sample: 20142016

Periods included: 3

Cross-sections included: 96

Total panel (balanced) observations: 288

\begin{tabular}{|c|c|c|c|c|}
\hline \multicolumn{5}{|c|}{ Coefficien } \\
\hline Variable & $\mathrm{t}$ & Std. Error & t-Statistic & Prob. \\
\hline KL & 0.031294 & 0.002914 & 10.73969 & 0.0000 \\
\hline LEV & $1.81 \mathrm{E}-05$ & $4.52 \mathrm{E}-06$ & 4.003599 & 0.0001 \\
\hline $\mathrm{C}$ & 0.308911 & 0.009346 & 33.05118 & 0.0000 \\
\hline \multicolumn{5}{|c|}{ Effects Specification } \\
\hline
\end{tabular}

Cross-section fixed (dummy variables)

\begin{tabular}{lll}
\hline \hline R-squared & 0.995599F-statistic & 436.3036 \\
Adjusted R-squared & 0.993317Prob(F-statistic) & 0.000000 \\
\hline \hline
\end{tabular}

Hasil pengujian hipotesis di lakukan dengan menggunakan regresi berganda di peroleh hasil sebagai berikut :

Pengaruh kinerja lingkungan terhadap corporate social responsibility (CSR) disclosure.

a. Kinerja lingkungan berpengaruh positif terhadap Pengungkapan corporate social responsibility, hasil ini dibuktikan dengan nilai koefisien regresi 0,0312 dan signifikasi $0,000<0,05$. Dengan demikian dapat disimpulkan bahwa H1 diterima, sehingga hipotesis yang menyatakan dugaan adanya pengaruh positif antara kinerja lingkungan terhadap Pengungkapan corporate social responsibility $(C S R)$ diterima. hal ini mengindikasikan perusahaan yang mengikuti PROPER tentu akan mengungkapkan Corporate Social Responsibility Disclosure yang lebih tinggi, sebab 
perusahaan akan lebih memperhatikan lingkungan dan membahasnya di laporan keuangan sebagai suatu keberhasilan dan kepedulian perusahaan terhadap lingkungan. Sesuai dengan teori Corporate Social Responsibility itu sendiri bahwa perusahaan yang peduli terhadap lingkungannya akan mengungkapkan Corporate Social Responsibility nya. Penelitian ini mendukung penelitian yang telah dilakukan Suratno,dkk (2006),Bahri dan Cahyani (2016),Rakhiemah dan Agustia (2009) dan Wardhani dan Toto (2013) yang menunjukan bahwa kinerja lingkungan berpengaruh positif terhadap pengungkapan Corporate Social Responsibility.

b. Leverage berpengaruh positif terhadap Pengungkapan corporate social responsibility, hasil ini dibuktikan dengan nilai koefisien regresi 1.81E-05dan signifikasi 0,000< 0,05. Dengan demikian dapat disimpulkan bahwa $\mathrm{H} 2$ diterima, sehingga hipotesis yang menyatakan dugaan adanya pengaruh positif antara leverage terhadap Pengungkapan corporate social responsibility diterima. Perusahaan yang memiliki leverage tinggi akan melakukan pengungkapan sosial dalam laporan tahunan perusahaannya alasan yang mendasar perusahaan yang memiliki leveragenya tinggi akan mengungkapkan kegiatan sosial untuk memenuhi kebutuhan informasi krediturnya. Penelitian ini mendukung penelitian yang telah dilakukan Nursiam dan Gemitasari (2013),Munsaidah,dkk (2016) yang menyatakan bahwa Leverage berpengaruh positif terhadap pengungkapan Corporate Social Responsibility . Hasil ini tidak sesuai dengan Teori Agensi yang menyatakan bahwa Leverage mempunyai pengaruh negative terhadap pengungkapan informasi Corporate Social Responsibility. Teori ini mendukung hasil yang di lakukan Marzully dan Denies (2012) yang menunjukan hasil pengaruh negative dan signifikan terhadap pengungkapan Corporate Social Responsibility.

\section{KESIMPULAN}

Dari dua faktor yang diteliti kinerja lingungan dan Leverage terbukti bahwa kinerja lingungan dan Leverage berpengaruh terhadap pengungkapan Corporate Social Responsibility. Hal ini berarti kinerja lingkungan dan Leverage mendorong perusahaan untuk melakukan pengungkapan Corporate Social Responsibility.

\section{REFERENSI}

Aditya Virgiwan Permana, Raharja. (2012). Pengaruh Kinerja Lingkungan Dan Karakteristik Perusahaan Terhadap Corporate Social Responsibility (CSR) Disclosure.Jurnal Universitas Dipenogoro.

Bahri, Syaiful dan Febby Anggista Cahyani.2016.Pengaruh Kinerja Lingkungan Terhadapat Kinerja Corporate Financial Performance dengan Corporate Sosial Responsibility Disclousure sebagai Variabel Intervening.Malang:EkoNika, Vol.1 No.2

Barnas, Alyssa Natasya et. al, "Pengaruh Profitabilitas dan Ukuran Perusahaan Terhadap Pengungkapan Corporate Social Responsibility (Studi Empiris Pada Perusahaan Subsektor Makanan dan Minuman yang Terdaftar di Bursa Efek Indonesia tahun 2011-2014)", Jurnal Fakultas Ekonomi dan Bisnis, Universitas Telkom, 2016.

Belkaoui, A. dan P. G. Karpik. 1989. Determinants of the Corporate Decision to Disclose Social Information. Accounting. Auditing and Accountability Journal.Vol. 2.No. 1. pp. 36-51.

Brigham, E. F. dan J. F. Houston. (2001). Manajemen Keuangan. Edisi Kedelapan. Jilid II. Penerbit Erlangga. Jakarta.

Dermawan, Decky dan Deitiana, Tita. 2014.Faktor-Faktor yang Mempengaruhi Pengungkapan Corporate Social Responsibility. Jurnal Bisnis dan Akuntansi Vol. 16 No 2. 
Munsaidah, Siti dkk., 2016., “Analisis Pengaruh Firm Size, Age, Profitabilitas, Leverage, Dan Growth Perusahaan Terhadap Corporate Social Responsibility (CSR) Pada Perusahaan Property Dan Real Estate Yang Terdaftar Di Bursa Efek Indonesia Pada Tahun 2010-2014". Journal Of Accounting, Volume 2 No.2 Maret 2016.

Nur, Marzully dan Denies Priantinah.2012.Analisis Faktor - Faktor yang Mempengaruhi Pengungkapan Corporate Social Responsibiity di Indonesia (Studi Empiris Pada Perusahaan Berkategori High Profile yang Listing di Bursa Efek Indonesia).Jurnal Nominal, Volume 1, No. 1, 22-34.

Nursiam dan Rina Gemitasari.2013.Analisis Faktor- Faktor yang Mempengaruhi Pengungkapan Tanggung Jawab Sosial Perusahaan ( Studi Empiris pada Perusahaan Manufaktur yang Terdaftar di Bursa Efek Indonesia Tahun 2009-2011).Surakarta : Proceeding Seminar Nasional dan Call for Paper Sancall 2013, ISBN: 978-979-636$147-2$

Rakhiemah, Aldilla Noordan Dian Agustia. 2009. Pengaruh Kinerja Lingkungan Terhadap Corporate Social Responsibility dan Kinerja Finansial. UniversitasAirlangga.

Rindawati, Meita Wahyu dan Nur Fadjrih Asyik. 2015. Pengaruh Profitabilitas ,Ukuran Perusahaan, Leverage dan Kepemilikan Publik terhadap Pengungkapan Corporate Social Responsisibility (CSR).Surabaya. Jurnal Ilmu \& Riset Akutansi Vol. 4 no. 6

Sembiring, Eddy Rismanda .2005.Karakteristik Perusahaan dan Pengungkapan Tanggung Jawab Sosisal: Study Empiris Pada Perusahaan Yang Tercatat di Bursa Efek Jakarta.Solo: SNA VIII

Suratno, Ignatius Bondan, dkk. 2006. "Pengaruh Environmental Performance terhadap Environmental Disclosure dan Economic Performance (Studi Empiris Pada Perusahaan Manufaktur yang Terdaftar di Bursa Efek Jakarta Periode 2001-2004)". Simposium Nasional Akuntansi IX.Padang, (23-26 Agustus).

Wardhani, Devinta Galuh dan Sugiharto, Toto, "Pengaruh Kinerja Keuangan, Ukuran Perusahaan, dan Kinerja Lingkungan Terhadap Intensitas Pengungkapan Pelaksanaan Tanggung Jawab Sosial Perusahaan Manufaktur Yang Terdaftar di Bursa Efek Indonesia", Proceeding PESAT (Psikologi, Ekonomi, Sastra, Arsitektur \& Teknik Sipil). Vol. 5 Oktober 2013.

Wijaya, Maria .2012. Faktor-Faktor yang Mempengaruhi Pengungkapan Tanggung Jawab Sosial pada Perusahaan Manufaktur yang terdaftar di Bursa Efek Indonesia.Jurnal Ilmiah Mahasiswa Akutansi : Vol 1, No. 1, Januari 2012 
